\section{Socio-Demographic Variables and Psychosocial Stressors Among Integrated Counseling and Testing Centre (ICTC) At- tendees: A Preliminary Report from North India}

Vijaya Lakshmi Nag ${ }^{1}$, Nihar Ranjan Dash ${ }^{2 *}$, Akansha Srivastava $^{3}$, Durgesh Kumar Srivastava ${ }^{3}$, Santosh Kumar Maurya ${ }^{3}$, Tapan Nirodhchandra Dhole ${ }^{3}$

${ }^{1}$ Department of Microbiology, All India Institute of Medical Sciences, Jodhpur, India

${ }^{2}$ Department of GI Surgery, All India Institute of Medical Sciences, New Delhi, India

${ }^{3}$ Sanjay Gandhi Post Graduate Institute of Medical Sciences, Lucknow, All India Institute of Medical Sciences, New Delhi, India

\begin{abstract}
\section{Background and objectives}

Integrated Voluntary Counseling and Testing Centers (ICTCs) cater to populations at high risk of acquiring HIV as well as the HIV positives. The present study was aimed at assessing the demographic variables, and primary psychosocial stressors among ICTC attendees.

Method

All the ICTC attendees formed this descriptive study population without any exclusion criteria. Prescribed proforma containing study questionnaires were filled up prior to and after the testing for HIV.

Results

288 of 311 attendees were screened (mean age 29.3 years). $25 \%$ were HIV positives. $22 \%$ of these were children ( $\leq 14$ years). All 311 attendees underwent pre-test counseling. 255 (88.5\%) attended post-test counseling. The major psychosocial stressors were: the concern about the future of family members $(49 \%)$ and the financial concerns $(33 \%)$. Multiple stressors were present in $80.7 \%$ attendees. The heterosexual mode of contact was the commonest $(75 \%)$ mode of HIV transmission.
\end{abstract}

${ }^{*}$ Corresponding author: Dr. Nihar Ranjan Dash, Department of GI Surgery, Al India Institute of Medical Sciences, New Delhi, India, Tel: +9111 26594879; Email: nagranjan@gmail.com

Citation: Nag VL, Dash NR, Srivastava A, Srivastava DK, Maurya SK, et al. (2016) Socio-Demographic Variables and Psychosocial Stressors Among Integrated Counseling and Testing Centre (ICTC) Attendees: A Preliminary Report from North India. J AIDS Clin Res Sex Transm Dis 3: 006.

Received: December 16, 2015; Accepted: March 16, 2016; Published: March 31, 2016

\section{Interpretation and conclusion}

HIV infected pediatric age group surfaces in this study. The psychosocial stressors do prevail among the patient as well as the high risk population. The knowledge of anticipated stressors may be helpful in imparting better counseling to these populations.

Keywords: Counseling; Psychosocial stressors; HIV; ICTC

\section{Introduction}

According to UNAIDS (2008), the number of HIV-infected people in India ranged between 2.0 and 3.1 million (UNAIDS, 2008). More than 90 percent of these infections were acquired through one of the following three horizontal routes: heterosexual contact, homosexual contact and intravenous drug use [1]. In order to control the surge in HIV incidence in a vastly populated country like India, the routes of transmission were needed to be checked and prevented through establishment of gateways throughout the country. It was with this aim that the National AIDS Control Organization (NACO) had set up several Voluntary Counseling and Testing Centers (VCTCs) across India. These are presently known as ICTCs (Integrated Counseling and Testing Centers). These are recognized as crucial corridors for provision of effective strategies for HIV prevention and care. ICTCs provide access to gain self help for HIV prevention, care, and treatment. These are means to create awareness, mobilize local responses and to reduce psycho-social stigmas following HIV infection such as denial, stigma and discrimination [2,3].

The social stigma of AIDS continues to prevail. Even though the numbers of attendees continue to rise in the ICTCs, sero-positive subjects do get detected at other places regularly. A few studies have been conducted previously stressing on socio-demographic variables [4].

Psycho-social aspect appeared to be a major factor potentially responsible for not undergoing voluntary counseling. A vast body of literature has focused on stress that is already prevailing among the HIV positive population $[5,6]$.

A review of the literature indicated that the knowledge of anticipated stress (the stress that one foresees) among the population at high risk of getting the disease is lacking in literature; therefore, the present study was undertaken with the objectives of (1) identifying the socio-demographic variables that characterize the clients visiting a ICTC in northern part of India, and (2) assessing the primary anticipated psychosocial stressors prevailing in this population. (the stressors that might arise in the event of being diagnosed as HIV positives).

\section{Material and Methods}

This prospective cross-sectional descriptive study was undertaken over a period of two years on volunteers attending the ICTC at Sanjay Gandhi Post Graduate Institute of Medical Sciences (SGPGIMS), Lucknow, Uttar Pradesh (UP), a tertiary care referral hospital in north India. Institutional ethical clearance was obtained for the study. All the attendees formed the study population without any exclusion criteria. Informed consent was obtained. In case of minors consents 
were taken from the parents. Proforma containing study questionnaires were filled up by the counselors from those who gave their consent. Two basic questions were asked. One of these was asked to list the worries coming to their mind before going in for testing. The second question was to list the fears in the event of a positive test result. The answers were classified into nine categories (Table 1). The data was collected through the set formats for pre-test and post-test counseling following the guidelines issued by the National AIDS Control Programme (NACO) [2]. Data analysis for the point estimate (prevalence percentage and mean) was calculated using SPSS software version 16 .

\begin{tabular}{|c|c|c|c|c|c|c|}
\hline (N=311) & \multicolumn{3}{|c|}{ Male (N=226) } & \multicolumn{3}{c|}{ Female ( N=85) } \\
\hline $\begin{array}{c}\text { Total } \\
\text { Attendees }\end{array}$ & Attendees & Tested & $\begin{array}{c}\text { HIV } \\
\text { Positive }\end{array}$ & Attendees & Tested & $\begin{array}{c}\text { HIV } \\
\text { Positive }\end{array}$ \\
\hline $\begin{array}{c}\text { Age in Yrs } \\
\text { (No.) }\end{array}$ & No (\%) & No (\%) & No (\%) & No (\%) & No (\%) & No (\%) \\
\hline$\leq 14(16)$ & $10(4.4)$ & $10(4.7)$ & $09(18)$ & $06(7.1)$ & $06(8.1)$ & $06(27.3)$ \\
\hline $15-19(12)$ & $05(2.2)$ & $04(1.9)$ & $01(02)$ & $07(8.2)$ & $05(6.7)$ & Nil \\
\hline $20-24(17)$ & $08(3.5)$ & $07(3.3)$ & $07(14)$ & $09(10.6)$ & $09(12.2)$ & $03(13.6)$ \\
\hline $25-29(91)$ & $73(32.3)$ & $68(31.8)$ & $11(22)$ & $18(21.2)$ & $17(23.0)$ & $03(13.6)$ \\
\hline $30-39(134)$ & $101(44.7)$ & $98(45.8)$ & $20(40)$ & $33(38.8)$ & $27(36.5)$ & $09(40.9)$ \\
\hline $40-49(36)$ & $25(11.1)$ & $23(10.7)$ & $02(04)$ & $11(12.9)$ & $09(12.2)$ & $01(4.5)$ \\
\hline$\geq 50(05)$ & $04(1.8)$ & $04(1.9)$ & Nil & $01(1.2)$ & $01(1.3)$ & Nil \\
\hline Total (311) & $226(72.7)$ & $214(68.8)$ & $50(16.1)$ & $85(27.3)$ & $74(23.8)$ & $22(7.1)$ \\
\hline
\end{tabular}

Table I: Age*, sex and HIV sero-positivity among the ICTC attendees.

*Age groups as defined by NACO (National AIDS Control Organization, India)

The socio-demographic variables recorded were age, sex, and HIV status. Primary psychosocial stressors were assessed as per the set format of pretest counseling which required the attendee to specify his/her anticipated source of stress (the stress they anticipated in case they were diagnosed as HIV positives). The stressors were thereafter categorized into different categories as specified in table 1.

From each client consenting to HIV screening, $2 \mathrm{ml}$ of blood was collected in a sterile vial by venous puncture. Serum was screened for HIV by using rapid kit [Advanced quality ${ }^{\mathrm{TM}}$ Rapid Anti-HIV (1\&2) Test (InTec Products, INC, Xiamen)]. HIV positive sera were further tested by two more types of rapid kits [SD-Bioline, immuno-chromatographic, HIV-1/2, Standard Diagnostics INC., Korea; HIV-TriDot (Immunochromatographic, BIOMED industries, Himachal Pradesh)] as per NACO guidelines [3]. Post test counseling was done preferably on the same day.

All the attendees, excepting the minors, were imparted pretest counseling. In case of 16 minors ( $\leq 14$ years) counseling was provided to one or both the parents. All of them were advised to attend the post test counseling.

\section{Results}

Three hundred eleven clients attended the ICTC during two year study period. The majority $(225 / 311,72.7 \%)$ were males. The mean age of attendees was 29.3 years. Two hundreds and eighty-eight (92.6\%) volunteers agreed for HIV testing. Seventy two (25\%) of them tested positive, of whom $68.8 \%$ were males. Maximum of attendees were in 25 to 39 years age group (Table 2). Interestingly maximum number of HIV positives was found in the youngest age group of $\leq 14$ years $(15 / 16 ; 93.7 \%)$ followed by younger age group of $20-24$ years $(10 / 16 ; 62.5 \%)$. All 311 participants including the parents of the minors were imparted pretest counseling. Among the participants who were tested $255(255 / 288 ; 88.5 \%)$ attended post-test counseling session. Heterosexual route was the commonest mode of transmission for HIV (54/72, 75\%). Of them 39 (78\%) were males and 15 (68.2\%) were females. Seventeen families (husband, wife and at least one child) were tested at the centre. Twelve (71\%) had at least one, $10(59 \%)$ had two and 7 (41\%) had more than two members infected with HIV.

\begin{tabular}{|c|c|}
\hline Psychosocial stressors & $\begin{array}{c}\text { ICTC Attendees } \\
\text { No (\%) }\end{array}$ \\
\hline $\begin{array}{c}\text { Family related (concerns pertaining to well being and future } \\
\text { of the family) }\end{array}$ & $137(46.4)$ \\
\hline Financial/Debt (treatment expenses ) & $102(34.6)$ \\
\hline Serious illness/death & $26(8.8)$ \\
\hline $\begin{array}{c}\text { Social (acceptance, segregation) } \\
\text { Loss of work (Being thrown out of job or inability to get a job) }\end{array}$ & $07(2.7)$ \\
\hline $\begin{array}{c}\text { Sex related (concerns related to ability to perform sexual } \\
\text { acts and/or to give birth) }\end{array}$ & $04(1.3)$ \\
\hline $\begin{array}{c}\text { Violence related (violence in the family on receiving a diag- } \\
\text { nosis of HIV positive) }\end{array}$ & $04(1.3)$ \\
\hline Addiction related (fear of continuing addiction) & $02(0.7)$ \\
\hline Others & $05(1.7)$ \\
\hline Multiple stressors( two or more) & $238(80.7)$ \\
\hline Table II: Primary Anticipated Psychosocial stressors (N=295*).
\end{tabular}

Among primary anticipated psychosocial stressors 'future of the family members' was the most common concern among the attendees (46.4\%), followed by 'financial insecurity' (34.6\%). Stressors related to other factors like sex, violence and addiction were also noted albeit in rarity. Multiple (two or more) stressors were observed in $80.7 \%$ of the attendees (Table 1).

\section{Discussion}

Several studies have addressed the issue of Socio-demographic profiles and psycho-social stressors among HIV infected population. The incidence of having stressors after knowing the HIV status varies in different population. In one of the studies from India $32 \%$ individuals did not show any emotion after knowing the positive result. Studies from India described the rate of depression and anxiety at $10-50 \%$ [7-9]. The incidence is lesser in western population and stands at $5-25 \%[10,11]$. The stress responses in Indian population included anger, shock, disbelief, grief, fear and guilt, etc.

However the scenario is different in individuals opting for a prophylactic check up in an ICTC. The stressors playing in their mind might affect their decision to get themselves tested and also might have a bearing in the aftermath of testing.

No study on anticipated psycho-social stressors (thoughts prior to the testing) could be found in literature. Hence we are discussing about the significant findings from our study.

The presence of maximum attendees in the age group of 25 to 39 years indicates that this age group perceived higher risk of HIV. These results are in agreement with the report from NACO [7] that the 25-39 years age group has the maximum number of AIDS cases in India [7]. Hence this group should be the focal point of targeted interventions of the ICTC. However the maximum HIV positivity in our study was in the age groups of $\leq 14$ years and 20 - 24 years. This is a new observation. In the youngest age group ( $\leq 14$ years) 9 children (all under 7 years of age) were HIV positive. All of them had HIV positive parents suggesting mother to child transmission (14/15, 93\%). However the 
mode of transmission of HIV in these parents was found to be the heterosexual route. The $20-24$ years age group had history suggestive of heterosexual route of transmission. Hence above all, the heterosexual route was the common route of transmission of HIV infection. This finding is consistent with various other studies [12-16].

Most of the participants who attended the pretest counseling also attended the post-test session. This may be attributed mainly to the rapid screening process which enabled the results to be declared within a few hours and therefore helped to reduce absenteeism. This was especially true for the outstation clients.

There was great concern about the future of the family members in case of the individual being diagnosed as HIV positive (family related stressors). The concern pertaining to financial matters were mainly the fear of losing job, becoming pauper, inability to afford the cost of treatment and a sense of financial insecurity looming large. This was especially if the person was the sole earning member of the family. Social stressors chiefly implied the stressors such as fear of being abandoned from the society, fear of being discriminated against, being ridiculed, etc. These findings may indicate that the knowledge of (i) AIDS being a treatable disease (ii) facilities available for free testing and counseling and (iii) free availability of antiretroviral drugs through organizations like NACO, needed further propagation. ICTCs are suitable centers for the above purpose.

Vertical transmission was found to be an important factor for spread of HIV. There are many risk factors described in literature. Strong association has been shown with maternal viral load, AIDS, Immunodeficiency, mode of delivery, duration of membrane rupture, prematurity, breast feeding and breast health.

Measures like elective cesarean section, antisepsis at birth, avoidance of breast feeding and ART therapy can significantly reduce the vertical transmission of HIV.

Behavioral changes in mother, voluntary counseling, ART prophylaxis, modification of infant feeding habits and immune-nutrition are effective option for prevention of vertical transmission related problem $[17,18]$.

Pre \& post test counseling in ICTC can help in providing the above knowledge and services especially to the population in developing countries.

Psychological stress has been suggested to have a biological effect on susceptibility to HIV infection [19]. The impact may be through multiple pathways namely immune modulation or change in genetics. This may further stress the importance of early psychological services offered in ICTCs.

\section{Conclusion}

Among the population attending ICTC the young generation had the maximum prevalence for HIV. The HIV positivity among the pediatric age group was a matter of concern and needed larger screening studies. The knowledge of anticipated stressors prevailing among the individuals infected with HIV as well as the high risk population might help in evolving a structured program of counseling, education and psychological support at the ICTC. This study addresses a certain population cohort. Larger population based studies may be required to validate the results.

\section{Acknowledgement}

Authors are grateful to the Uttar Pradesh State AIDS Control Society (UPSACS) and NACO for setting up the ICTC at SGPGIMS, Lucknow and giving permission for publication of the data.

\section{What is Already Known on this Subject?}

AIDS continues to be a dreaded disease. In order to provide testing, counseling and treatment at a single door step, Integrated Counseling and Testing Centers (ICTC, VCTC) are functioning. Studies are available regarding the socio demographic pattern, effectiveness of therapy, counseling and detection of coexistent illness, etc.

\section{What Does this Study Add?}

ICTC provides an ideal cohort to study the prevalence of psycho-social stressors that has a bearing in the counseling. The result of the study would help in identifying them. This would help in conducting similar studies in larger population so as to identify factors that could be incorporated in the counseling protocol in the ICTCs. The study also highlights the socio-demographic pattern in north India, particularly focusing the insurgence of pediatrics age group.

\section{References}

1. UNAIDS (2008) Report on the global AIDS epidemic. Geneva: UNAIDS, Switzerland.

2. National AIDS Control Organization (NACO) (1992) Ministry of health and family welfare Government of India. New Delhi, India.

3. Jamia Millia Islamia (2007) Voluntary Counseling and Testing Center (VCTC). Event, Jamia Millia Islamia, New Delhi, India.

4. Chu HY, Crump JA, Ostermann J, Oenga RB, Itemba DK (2007) Sociodemographic and clinical characteristics of clients presenting for HIV voluntary counselling and testing in Moshi, Tanzania. Int J STD AIDS 16: 691-696.

5. van der Veek SM, Kraaij V, Van Koppen W, Garnefski N, Joekes K (2007) Goal disturbance, cognitive coping and psychological distress in HIV-infected persons. J Health Psychol 12: 225-230.

6. McCain NL, Cella DF (1995) Correlates of stress in HIV disease. West J Nurs Res 17: 141-155

7. Agrawal M, Srivastava K, Goyal S, Chaudhury S (2012) Psychosocial correlates of human immunodeficiency virus infected patients. Ind Psychiatry J 21: 55-60.

8. Perkins DO, Stern RA, Golden RN, Murphy C, Naftolowitz D, et al. (1994) Mood disorders in HIV infection: prevalence and risk factors in a nonepicenter of the AIDS epidemic. Am J Psychiatry 151: 233-236.

9. Summers J, Zisook S, Atkinson JH, Sciolla A, Whitehall W, et al. (1995) Psychiatric morbidity associated with acquired immune deficiency syndrome-related grief resolution. J Nerv Ment Dis 183: 384-389.

10. Chandra PS, Ravi V, Desai A, Subbakrishna DK (1998) Anxiety and depression among HIV-infected heterosexuals--a report from India. J Psychosom Res 45: 401-409.

11. Krishna VA, Chandra PS (1998) Concerns and psychiatric morbidity among people living with HIVIAIDS. NIMHANS J 17: 253-260.

12. National AIDS Control Organization (2006) Technical reports - India HIV Estimates 2006. National AIDS Control Organization, Department of Health \& Family Welfare, Ministry of Health \& Family Welfare, Government of India, New Delhi, India.

13. Arora DR, Gautam V, Sethi S, Arora B (2004) A 16-year study of HIV sero prevalence and HIV-related diseases in a teaching tertiary care hospital in India. Int J STD AIDS 15: 178-182. 
Citation: Nag VL, Dash NR, Srivastava A, Srivastava DK, Maurya SK, et al. (2016) Socio-Demographic Variables and Psychosocial Stressors Among Integrated Counseling and Testing Centre (ICTC) Attendees: A Preliminary Report from North India. J AIDS Clin Res Sex Transm Dis 3: 006.

- Page 4 of $4 \cdot$

14. Anvikar AR, Chakma T, Rao VG (2005) HIV epidemic in Central India: trends over 18 years (1986-2003). Acta Trop 93: 289-294.

15. Pisani E, Garnett GP, Grassly NC, Brown T, Stover J, et al. (2003) Back to basics in HIV prevention: focus on exposure. BMJ 326: 1384-1387.

16. UNAIDS (2004) 2004 Report on the global AIDS epidemic. 4th global report, Joint United Nations Programme on HIVIAIDS (UNAIDS), Geneva Switzerland.
17. Volmink J, Marais B (2008) HIV: mother-to-child transmission. BMJ Clin Evid.

18. Marie-Louise N (2001) Prevention of mother-to-child transmission of HIV: challenges for the current decade. Bull World Health Organ 79: 1138-1144.

19. Joly M, Odloak D, Rondo PHC (2016) Human Immunomodulation and initial HIV spread. Comput Chem Eng 84: 255-280. 